\title{
UTILIZAÇÃO DA CINZA DA CASCA DO COCO VERDE COMO SUBSTITUIÇÃO PARCIAL DO CIMENTO PORTLAND EM ARGAMASSAS
}

\author{
Use of gray bark of green coconut as replacement partial \\ cement Portland in mortar.
}

\author{
Samile Raiza Carvalho Matos ${ }^{1}$, Cleidson Carneiro Guimarães ${ }^{2}$
}

Recebido em 17 de junho de 2016; recebido para revisão em 19 de julho de 2016; aceito em 28 de novembro de 2016; disponível on-line em 29 de março de 2017.

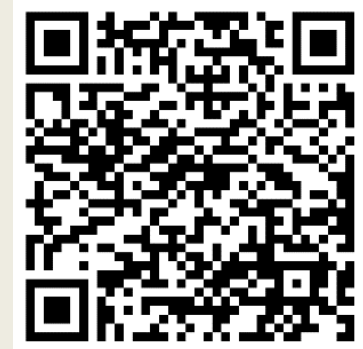

PALAVRAS CHAVE:

Adição mineral;

Resíduo;

Casca de coco verde;

Pozolanicidade;

Argamassa.

KEYWORDS:

Mineral addition;

Residue;

Green coconut shell;

Pozzolanicity;

Motar.

* Contato com os autores:

${ }^{1}$ e-mail: samilercm@gmail.com (S. R. C. Matos )

Bacharela em Ciências Exatas e Tecnológicas, Graduada em Engenharia Civil pela Universidade Federal do Recôncavo da Bahia(UFRB).

${ }^{2}$ e-mail: cleidsonguimaraes@ufrb.edu.br (C. C. Guimarães)

Professor do Centro de Ciências Exatas e Tecnológicas (CETEC) da Universidade Federal do Recôncavo da Bahia. cinza da casca de coco verde (CCCV) nas propriedades das argamassas no estado fresco e endurecido, a partir da substituição parcial do cimento Portland (CP) por cinza. Esta proposta surge da problemática ligada à destinação da casca do coco como resíduo urbano e agroindustrial e dos impactos ambientais provocados pela produção do cimento Portland. Para realização dessa pesquisa foram produzidas uma argamassa de referência e outras três argamassas com diferentes teores de substituição do CP por CCCV. Inicialmente, foi feita a caracterização dos materiais utilizados no trabalho e a análise de índice de pozolanicidade da cinza. Em seguida, foram feitas análises referenciais das propriedades das argamassas produzidas no estado fresco e no estado endurecido. A partir das análises pode-se perceber que a presença da cinza na argamassa influencia na trabalhabilidade, resistência mecânica e na durabilidade da argamassa e que a CCCV não possui potencial pozolânico. A adição de até $10 \%$ de CCCV substituindo o cimento Portland é viável.

ABSTRACT: This study aims to evaluate the influence of ash green coconut shell (AGCS) on the properties of mortars in fresh and hardened, from the partial replacement of Portland cement $(P C)$ by gray. This proposal arises from problems linked to the allocation of coconut shell as urban and agro-industrial waste and environmental impacts caused by the production of Portland cement. For this survey were produced a reference mortar and three mortars with different $C P$ replacement levels by AGCS. Initially, it was the characterization of the materials used at work and ash pozzolanicity index analysis. Next, analyzes were made reference the properties of mortars produced in fresh and hardened state. From the analysis it can be seen that the ash presence in the mortar influences the workability, strength and durability of the mortar and the CCCV not have pozzolanic potential. The addition of up to $10 \%$ AGCS replacing the Portland cement is feasible.

RESUMO: O presente trabalho tem como objetivo principal avaliar a influência da 


\section{INTRODUÇÃO}

Nos últimos anos, tem-se notado a intensificação de áreas de cultivo de coco em várias partes do mundo e no Brasil a situação não é diferente. Segundo a Food and Agriculture Organization of the United Nations (2014) o Brasil é o quarto maior produtor de coco, ficando atrás apenas da Indonésia, Filipinas e da Índia. Esse crescimento é impulsionado graças à promissora tendência de produção de sua água, cujo consumo está associado à qualidade de vida e à saúde. Partindo disso, as empresas brasileiras passaram a apostar no comércio da água de coco, inclusive para exportação. Fato que colocou o Brasil em destaque no cenário mundial de produção da bebida (MARTINS, 2014).

No panorama nacional, o Nordeste é a região que mais se destaca no cultivo do coco. De 1990 a 2013, a produção desse fruto no Brasil praticamente dobrou, chegando a 1,9 bilhões de frutos, e o Nordeste foi responsável por $68 \%$ dessa produção. $O$ grande número de cidades litorâneas e turísticas nesta região estimula o comércio desse fruto e justifica essa produção (JESUS JR et al., 2015).

Em consequência desse crescimento, a quantidade de casca de coco verde gerada como resíduo agroindustrial e urbano, tem aumentado bastante. Sabe-se que esse resíduo corresponde a uma parcela significativa do peso do fruto in natura, cerca de $90 \%$, e que o peso médio do coco após a retirada da água é de $1,5 \mathrm{Kg}$. Sendo assim, só na região nordeste foi gerado, 1,95 milhões de toneladas de casca de coco verde, apenas em 2013 (CORRADINI et al., 2009; SILVEIRA, 2008).

O acúmulo dessas cascas em locais inadequados na zona urbana, além de causar um efeito deletério à imagem da cidade, tem acarretado uma série de problemas econômicos e ambientais para os municípios, uma vez que, afeta os serviços municipais de coleta, transporte e

\footnotetext{
${ }^{1}$ Cabe destacar o potencial da indústria da construção em absorver resíduos de outros setores pode não significar a efetiva substituição. A efetiva inserção de resíduo em produtos da construção civil deve ser
}

deposição de lixo, por conta do grande volume que ocupa e do tempo de decomposição que pode chegar a 12 anos. Junto a isso, a sua forma e constituição dificultam a sua compactação, o que aumenta a demanda por área nos aterros e provoca a redução da vida útil dos mesmos (CORRADINI et al., 2009; AGENCIA BRASIL, 2004). Diante disso, o reaproveitamento das cascas de coco verde surge como uma necessidade econômica e ambiental.

Existe uma tendência de aproveitamento da casca do coco como matéria prima para diversos setores de produção, inclusive como biomassa para geração de energia. Segundo Nogueira et al. (2000), o coco residual tem um poder calorífico superior (PCS) de cerca de $5.447,38 \mathrm{kcal} / \mathrm{kg}$ (base seca) o que possibilita este resíduo ser queimado diretamente em fornalhas ou aproveitado para a produção de carvão vegetal ou briquetes. Por conta deste potencial calorífico, algumas empresas já utilizam a casca do coco como fonte de energia. A partir desse processo, um dos resíduos sólidos gerados pela produção da energia é a cinza da casca do coco verde (CCCV).

Este resíduo pode se transformar em um subproduto a partir do momento em que ele é inserido na cadeia produtiva para fabricação de novos artefatos (VALLE, 1995). Uma possibilidade é a utilização da CCCV na construção civil, pois esse é o setor industrial que mais consome recursos ambientais, chegando a consumir de $20 \%$ a $50 \%$ do total dos recursos naturais. Ao mesmo tempo é o que tem maior potencial ${ }^{1}$ de absorver resíduos de outros setores, segundo Sjötrön (apud DAL MOLIN 2005). Paralelo a isso, a indústria da construção civil vive um grande desafio que é possibilitar um desenvolvimento tecnológico de forma mais sustentável, principalmente por conta dos danos ambientais associados à produção do cimento Portland (CP).

Uma alternativa para a utilização da CCCV, pelo setor da construção civil, é como adição

antecedido de estudo cuidadoso. Este deve indicar que a inserção do resíduo melhora ou, no mínimo, não diminui parâmetros de resistência e durabilidade. 
mineral em substituição parcial do cimento Portland. Já existem diversos estudos que apontam para a utilização de cinzas de biomassa na produção de materiais de construção, a exemplo casca de arroz (MEHTA, 1977); bagaço de cana-de-açúcar (CORDEIRO; TOLEDO FILHO; FAIRBAIRN, 2009a); resíduo de óleo de palma (TANGCHIRAPAT; JATURAPITAKKUL, 2010). Essas cinzas possuem propriedades que atendem aos requisitos para serem utilizados como adições minerais em cimentos compostos.

\subsection{ADIÇÕES MINERAIS}

Segundo a NBR 11172 (ABNT, 1990) o termo "adição" deve ser empregado para designar "produto de origem mineral adicionado aos cimentos, argamassas e concretos, com a finalidade de alterar suas características". Pode-se dizer também, que as adições minerais quando empregadas conjuntamente com o cimento Portland, modificam as propriedades dos materiais cimentícios proporcionando um melhor desempenho tecnológico (CORDEIRO, 2006). Em alguns casos, pode haver redução dos custos de produção por conta da substituição de uma parcela de clínquer ${ }^{2}$ por materiais energeticamente menos nobres, uma vez que as adições minerais são obtidas, geralmente, a partir de resíduos industriais ou agroindustriais.

Além de benefícios tecnológicos e econômicos, do ponto de vista ambiental, a utilização de adições minerais é benéfica, pois pode reduzir os índices de poluição causados pelo descarte dos resíduos. Aliado a isso, o uso de adições minerais pode promover a preservação das jazidas de calcário e argila e a redução da emissão de $\mathrm{CO} 2$ e outros gases intensificadores do efeito estufa (CO, CH4, NOX, NO2 e SO2), gerados durante a fabricação do cimento Portland (CORDEIRO, 2006).

Segundo a NBR 11172 (ABNT, 1990), as adições minerais podem ser classificadas quanto a sua ação físico-química em três tipos: inertes, cimentantes e pozolânicas.

As adições minerais do tipo inertes/fíler são materiais essensialmente finos e uniformes, cuja ação é puramente física e não possuem nenhuma atividade química, no sentido da produção de $\mathrm{C}-\mathrm{S}-\mathrm{H}$. Essas adições promovem o efeito do empacotamento granulométrico e funcionam como ponto de nucleação para hidratação dos grãos de cimento. Quando presentes em pequena quantidade (normalmente menos que $15 \%$ da massa do cimento) proporcionam melhorias sobre as propriedades da massa como trabalhabilidade, massa específica, porosidade e exsudação e a tendencia a fissuração (DAL MOLIN, 2005; NEVILLE, 1997; OLIVEIRA, 2000). A NBR 11578 (ABNT, 1991) que trata do cimento Portland composto, estabelece que o teor de fíler incorporado deve variar de 6 a10\% da massa do cimento e que um material carbonático ou fíler deve ter no mínimo 85\% de CaCO3.

\subsection{EFEITO DAS ADIÇÕES MINERAIS}

Para diversos autores, (CASTRO; PANDOLFELLI, 2009; LAWRENCE; CYR; RINGOT, 2003; BONAVETTI, RAHHAL, 2006), normalmente, as adições minerais inertes promovem três efeitos físicos principais sobre a hidratação do cimento Portland:

- diluição do cimento;

- $\quad$ redistribuição na granulometria;

- nucleação heterogênea.

A diluição do cimento Portland é equivalente ao aumento da relação água/cimento. Tanto maior o teor de substituição, menor a quantidade de cimento Portland acarretando menor teor de hidratos produzidos ao longo do tempo (CASTRO; PANDOLFELLI, 2009; LAWRENCE; CYR; RINGOT, 2003).

A distribuição na granulometria depende da finura e da quantidade de inerte utilizado e promove alteração na porosidade inicial da mistura

${ }^{2}$ O clínquer é o principal constituinte do cimento, cujo processo de fabricação envolve a calcinação de rochas calcarias. 
(LAWRENCE; CYR; RINGOT, 2003). Esse fenômeno ocorre devido à localização das partículas inertes entre os grãos de cimento, promovendo o aumento da área de contato entre cimento e água, consequentemente contribuindo com a velocidade de hidratação do cimento e com a formação de C-S-H (BONAVETTI, RAHHAL, 2006).

$O$ terceiro efeito (nucleação heterogênea) é tanto mais significativo quanto maior a finura do material adicionado. Lawrence; Cyr e Ringot (2003) definem a nucleação heterogênea como um processo físico que promove a ativação do cimento Portland. Trata-se, portanto, de um fenômeno catalítico no qual um material reduz a energia de ativação de uma reação química sem que haja consumo da espécie química que ativa, funcionando apenas como uma superfície onde ocorre a hidratação.

As adições minerais cimentantes possuem uma hidratação lenta e a quantidade de C-S-H (Siliato de Cálcio Hidratado) produzida não é suficiente para que essas adições sejam empregadas com fim estrutural. Elas não necessitam de hidróxido de cálcio para formar os produtos cimentantes $\mathrm{C}-\mathrm{S}-\mathrm{H}$, mas quando usada em substituição parcial do cimento Portland ou como adição, a presença dos produtos da hidratação do cimento como gipsita e $\mathrm{Ca}(\mathrm{OH})_{2}$ aceleram a sua hidratação, potencializando a formação de C-S-H (DAL MOLIN, 2005). A escória granulada de alto forno é um exemplo desse tipo de adição.

Já os materiais pozolânicos são definidos pela NBR 12653(ABNT, 2014) como materiais silicosos ou sílico-aluminosos que por si só possuem pouca ou nenhuma atividade aglomerante, mas que, quando finamente moídos e na presença de água, fixam o hidróxido de cálcio à temperatura ambiente, formando compostos com propriedades hidráulicas. Diferente das adições cimentantes, as adições pozolânicas precisam do hidroxido de

${ }^{3}$ O hidróxido de cálcio é produto da hidratação do silicato tricálcico que origina cristais de C-S-H (fibrosos) e de $\mathrm{CH}$ (maciços).

4 A nucleação heterogenea ocorre quando partículas extremamente finas são adicionadas a mistura e cálcio3 resultante da hidratação do cimento para produzir o C-S-H e os aluminatos hidratados. Dessa forma a atividade pozolânica consiste na formação de produtos de hidratação secundários, tendendo a preencher os vazios capilares com material C-S-H de baixa densidade e não orientados (MEHTA e MONTEIRO, 2008).

De forma geral, as adições minerais provocam efeitos físicos ou químicos sobre os produtos cimentícios. Entre os efeitos físicos está o efeito microfíler que consiste no aumento da densidade da mistura resultante da ocupação dos espaços vazios por micro partículas de adição, este fenômeno também pode ser entendido como redistribuição granulométrica. $O$ efeito de diluição do cimento portland que consiste na redução da concentração de cimento e consequentemente provoca uma redução na quantidade de produtos da hidratação. E por fim, o efeito de nucleação que a adição mineral funciona como ponto de nucleação4 e restringe o espaço para o crescimento dos cristais na superfície do cimento, ao passo que propicia um aumento na quantidade dos mesmos. Já o efeito químico consiste basicamente na formação de C-S$\mathrm{H}$ através dos produtos da hidratação do cimento.

Esses efeitos químicos e físicos das adições minerais interferem nas propriedades dos materiais cimentícios nos estados fresco e endurecido. No estado fresco a adição mineral pode influenciar nos aspectos reológicos, no consumo de água e no calor de hidratação. Já no estado endurecido, uma adição mineral pode interferir na resistência à compressão e a tração e na durabilidade desses materiais.

No estado fresco, o efeito das adições sobre os aspectos reológicos estão ligadas ao aumento da coesão, à redução da tendência de exudação e segregação dos agregados. Já quanto ao consumo de água, sabe-se que depende da superfície específica das partículas, da forma e da quantidade adicionada. Geralmente, o aumento no

preenchem os interstícios da superfície das partículas de clínquer, agindo de forma catalítica na reação de hidratação do cimento e possibilitando o crescimento de cristais nos interstícios entre a adição e a água (DAL MOLIN, 2005). 
teor de finos aumenta a demanda por água para se atingir uma mesma consistência. $\mathrm{O}$ calor de hidratação, normalmente, é reduzido no caso de substituição do cimento Portland (CP) por adição (DAL MOLIN, 2005). Caso a adição seja cimentante ou pozolânica a velocidade de hidratação é mais lenta do que a do CP, e não coincide a hidratação do cimento com a hidratação da adição havendo uma "diluição" do calor de hidratação ao longo do tempo. Já no caso do material inserido ser inerte, como não há reação e, portanto, não há liberação de calor.

Já no estado endurecido a adição mineral, geralmente, provoca um ganho de resistência à compressão por conta do processo de refinamento dos poros, e um ganho pouco significativo de resistência à tração por conta da diluição do cimento, no caso das adições inertes, mas no caso das adições pozolânicas ocorrerá um ganho expressivo nessa resistência após a formação dos C$\mathrm{S}-\mathrm{H}$ secundários, pois a quantidade e o tamanho dos cristais de $\mathrm{Ca}(\mathrm{OH})_{2}$ na zona de transição é reduzida com as reações. É comum também as adições interferirem na durabilidade, influenciando na porosidade capilar, por conta da redistribuição granumétrica, na resistência a sulfatos, na corrosão da armadura e na reação alcali agregado (DAL MOLIN, 2005).

Diante do potencial físico-químico de alterar as propriedades das matrizes cimentícias, no estado fresco e endurecido, espera-se que uma adição mineral promova uma economia do clínquer e realize alterações que proporcionem uma melhora no desempenho da pasta, argamassa ou concreto. A partir disso, a eficiência de uma adição está associada à capacidade de atuar sobre as propriedades mecânicas (ganho de resistência à tração e à compressão), propriedades no estado fresco (aspectos reológicos, consumo de água, fissuração por retração plástica) e durabilidade (redução da permeabilidade e absorção).

Essa eficiência das adições minerais depende diretamente da composição química, do grau de amorficidade, da granulometria e da quantidade utilizada. No caso do uso de cinza como adição mineral a eficiência está relacionada a vários fatores, entre eles o tipo de biomassa utilizada e as condições de queima (variação de temperatura, tipo de caldeira, etc.), pois estes fatores influenciam diretamente nas propriedades químicas e físicas da cinza e irão determinar seu efeito sobre os materiais à base de cimento, como pastas, argamassas e concretos.

Quanto à ação pozolânica, de acordo com a norma NBR 12653(ABNT, 2014) a cinza deve primariamente conter teores de sílica, alumina e ferro superiores a 70\%. A ação fíler ou pozolânica das cinzas é diretamente influenciada por sua finura, sendo desejável na composição granulométrica a presença de uma quantidade de material retido na peneira de abertura de malha de $45 \mu \mathrm{m}$ inferior a $34 \%$, de acordo com essa mesma norma.

Para melhorar a eficiência das cinzas de biomassa vários tratamentos vêm sendo aplicados visando aumentar a reatividade desses materiais. A queima das cinzas a altas temperaturas, com o objetivo de promover alteração da estrutura cristalina e aumentar o grau de amorfização dos materiais, e a moagem dos grãos, para aumento de sua finura, têm sido os mais aplicados (CORDEIRO; TOLEDO FILHO; FAIRBAIRN, 2008; SILVA, 2015).

A argamassa é um material largamente utilizado na construção civil, em diferentes tipos e fases de obra. Sendo aplicada, principalmente, no levante de alvenaria, assentamento cerâmico, revestimento de paredes e tetos, contrapisos assentamento e reparos estruturais. Nelas o cimento Portland é o principal aglomerante. Como parâmetros para a avaliação de uma argamassa fazse necessário avaliar algumas propriedades tanto no estado fresco como endurecido.

Dentre as propriedades fundamentais, destaca-se a trabalhabilidade, a densidade e a absorção. De acordo com a NBR 13281(ABNT, 2005) que trata das especificações das argamassas, elas são qualificadas a partir das seguintes propriedades: densidade de massa no estado fresco e teor de ar incorporado -NBR 13278(ABNT, 2005), densidade de massa aparente no estado endurecido- NBR 13280(ABNT, 2005), retenção de água- NBR 13277(ABNT, 2005), resistência de aderência à 
tração- NBR 13528(ABNT, 2010), resistência à compressão- NBR 7215(ABNT, 1996), resistência à tração na flexão NBR 13279(ABNT, 2005) e coeficiente de capilaridade NBR 15259(ABNT, 2005) Analisar essas propriedades é fundamental para compreender/prever o comportamento da CCCV em argamassas.

A trabalhabilidade é a propriedade da argamassa no estado fresco que determina o quão fácil é misturar, transportar e aplicar este material. Ela não é simples de se determinar, pois vai depender do tipo de substrato onde será aplicada e de um conjunto de outras propriedades, como plasticidade, retenção de água, coesão, exsudação, densidade de massa, adesão inicial e consistência (CARASEK,2007).

Com relação ao comportamento mecânico, principalmente a resistência à compressão, sabe-se que a argamassa deve adquirir rapidamente alguma resistência, permitindo o assentamento de várias fiadas no mesmo dia, bem como desenvolver resistência adequada ao longo do tempo. Apesar disso, não são necessárias resistências altas das argamassas de assentamento para garantir o bom desempenho das paredes; pelo contrário, a resistência da argamassa não deve nunca ser superior à do bloco (CARASEK, 2007). Para avaliar as propriedades mecânicas das argamassas pode ser feito o ensaio de resistência à tração na flexão e a compressão, previsto na NBR 13279 (ABNT, 2005).

\subsection{OBJETIVO}

A partir das análises de consistência, densidade de massa, resistência, e absorção, objetiva-se investigar a interferência da adição da CCCV em propriedades fundamentais das argamassas ligadas a trabalhabilidade, resistência e durabilidade e assim inferir se a mesma pode ser empregada como adição mineral.

\subsection{CONTEXTO DO TRABALHO}

Durante o processo de fabricação do cimento Portland é gerado uma elevada quantidade de partículas, desde as sólidas até gases. Estas podem permanecer em suspensão no ar prejudicar habitantes vizinhos às fábricas ( $A B D U L-W A H A B$, 2006; WILLS, 2013).

Dentre os gases poluentes gerados durante a produção do cimento Portland o gás carbônico tem especial destaque por sua contribuição ao efeito estufa. Inclusive destaca Benhelal et al. (2013) a indústria cimentícia é considerada como uma das maiores fontes de emissão de $\mathrm{CO} 2$ do planeta. Cerca de $5 \%$ a $7 \%$ das emissões globais desse gás são oriundas das fábricas de cimento Portland. São gerados $900 \mathrm{~kg}$ de gás carbônico por tonelada de cimento Portland produzido (BENHELAL et al. 2013).

Destaca Benhelal et al. (2013), que é por meio de estratégias adequadas, tais como a eficiência energética, a utilização de combustíveis alternativos, substituição do clínquer, as emissões podem ser reduzidas a ponto de chegar a 1,55 bilhões de toneladas em 2050.

Dessa forma, a depender do comportamento da CCCV, o coco pode ser apresentado como uma alternativa de material a ser absorvido pelo setor cimentício, na forma de adição mineral, que além de atender aos requisitos técnicos pode mitigar os danos ambientais provocados tanto pela indústria do coco quanto pela indústria do cimento.

\section{MATERIAIS E MÉTODOS}

A etapa experimental deste trabalho envolve confecção de corpos de prova de argamassa e a análise das propriedades. Inicialmente, foi feita a caracterização dos materiais utilizados no trabalho, esta etapa inclui a classificação granulométrica e a determinação da massa específica do agregado, do cimento e da cinza. Em seguida, foram feitos os ensaios que determina o potencial pozolânico da cinza utilizada. E por fim os ensaios que caracterizam a argamassa no estado fresco e endurecido ligadas à durabilidade e à resistência. Todas as etapas da pesquisa foram executadas no Laboratório de Materiais de Construção II da Universidade Federal do Recôncavo Baiano, em Cruz das Almas. 


\subsection{MATERIAIS}

\subsubsection{Cinza da casca do coco verde}

As cinzas utilizadas para a realização desta pesquisa foram produzidas a partir das cascas de cocos verdes descartados no centro de Cruz das Almas. Os cocos foram postos em estufa, onde permaneceram por 7 dias a $105 \pm 5$ 으, a fim de perder o máximo de umidade. Em seguida, eles foram partidos, para facilitar a queima, e colocados em um fogão artesanal (Figura 1c). Para produção desse fogão utilizou-se um balde metálico, dois tijolos e uma bacia metálica. $\mathrm{O}$ balde metálico possuía furos no fundo para possibilitar a circulação de gás oxigênio. A combustão ocorreu sem controle de temperatura ou teor de gás oxigênio, inclusive a combustão não ocorreu de forma completa apresentando elevado teor de carbono (Figura 1d).

Ao fim da combustão, a cinza residual era coletada do balde, colocada em cadinhos de porcelana e levada à Mufla (Figura 1e) com temperatura ${ }^{5}$ de $600^{\circ} \mathrm{C}$ por $30 \mathrm{~min}$. Este tratamento térmico adicional visou fornecer as condições para a combustão completa do material e, consequentemente, o menor índice de carbono nas cinzas (Figura $1 \mathrm{f}$ ). Ao fim dos $30 \mathrm{~min}$, a cinza foi removida imediatamente da mufla, para acelerar o resfriamento e obter amorfização da amostra, já que o esfriamento lento da cinza dentro da mufla possibilita a formação de estruturas cristalinas.

Em seguida, esta cinza (Figura 2a) foi colocada no moinho de facas ${ }^{6}$ tipo Willye Modelo STAR FT-60 Macro (Figura 2b) até que não houvessem grãos retidos na peneira mesh 30 (Figura 2c). Por fim, a cinza era conduzida ao moinho de bola com câmara fechada - Modelo SP-38 (Figura 2d) por $120 \mathrm{~min}^{7}$, originando a cinza utilizada neste trabalho e demonstrada na Figura 2e.

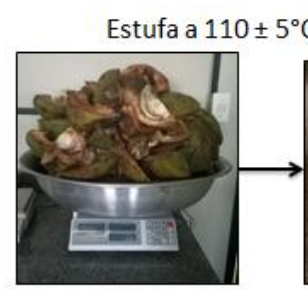

(a)

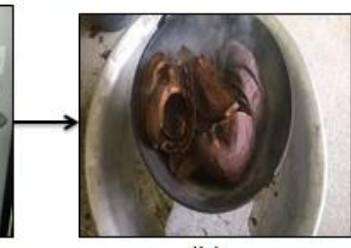

(b)

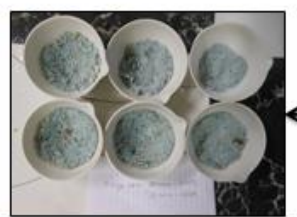

(f)

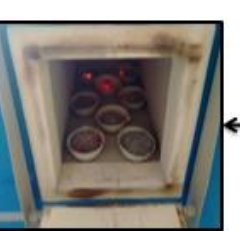

(e)

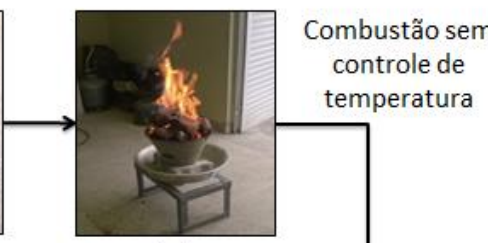

(c)

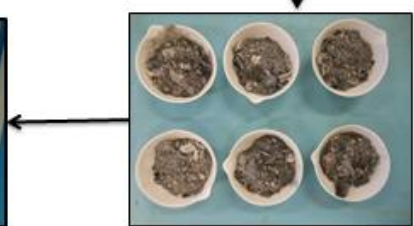

(d)

Murfla por $30 \mathrm{~min}$ a $600^{\circ} \mathrm{C}$

FIGURA 1:Tratamento térmico para produção da cinza da casca do coco verde, sendo: [a] pesagem do resíduo seco em estufa; [b] casca de coco em recipiente para queima prévia; [c] queima às condições ambiente; [d] cinza após queima prévia; [e] cadinhos na mufla; [f] cinza após queima na mufla.

FONTE: Autor (2016)

\footnotetext{
5 As cinzas de maior atividade pozolânica foram produzidas na faixa de temperatura entre $500^{\circ} \mathrm{C}$ e $600^{\circ} \mathrm{C}$ (CORDEIRO et al., 2006).

${ }^{6} \mathrm{O}$ moinho de facas funciona como um circuito fechado com classificador, onde as frações grossas só saem do processo quando atinge a finura especificada.
}

\footnotetext{
${ }^{7}$ Segundo Cordeiro, Toledo e Fairbairni (2008), a partir de um tempo de moagem de 120 min foi possível observar maiores índices de pozolanicidade (maior que 100\%) para a cinza da casca de arroz. Para tempos de moagem superiores a $120 \mathrm{~min}$ o aumento no Índice de pozolanicidade não foi tão significativo, destacam os autores.
} 
Moinho de Facas até que não tenha retido na peneira de 30 mesh

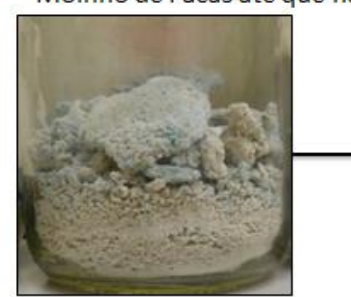

(a)

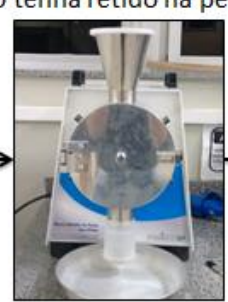

(b)

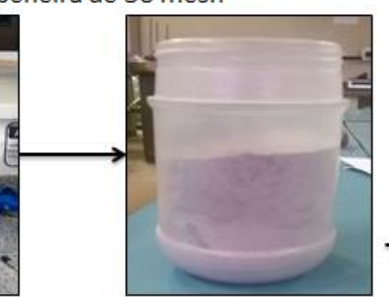

(c)

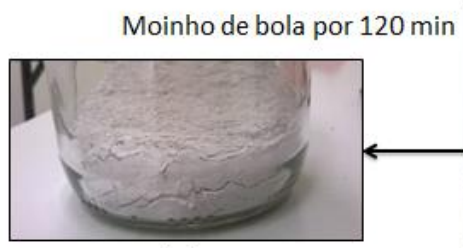

(e)

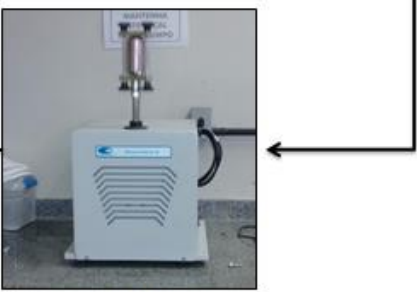

(d)

FIGURA 2: Processos de moagem para produção da cinza, sendo: [a] cinza após sair da mufla; [b] moinho de facas; [c] cinzas após passar pelo moinho de facas; [d] moinho de bola; [e] cinza após passar pelo moinho de bolas. FONTE: Autor (2016)

Por meio da utilização do pHmetro de mesa foi possível observar que ao inserir a cinza CCCV em meio aquoso, a altera $\mathrm{o} \mathrm{pH}$ da água tornando-a básica. A inserção de cerca $2 \mathrm{~g}$ de CCCV altera $\mathrm{opH}$ da água destilada, de 7,0, para 12. A massa específica da CCCV é de $2,22 \mathrm{~g} / \mathrm{cm}^{3}$. A massa específica foi determinada através da norma que trata do cimento NM 23(ABNT, 2001).

A massa específica da cinza foi determinada através da norma que trata do cimento a NM 23 (ABNT, 2001). E foi determinado o Ph da cinza com o uso de um pHmetro de bancada.

\subsubsection{Aglomerante e aditivo superplastificante}

Foram utilizados dois tipos de cimento nessa pesquisa, o cimento CP II F-32, para o ensaio de pozolanicidade, conforme a recomendação da NBR 5752 (ABNT, 2014) e para os demais ensaios foi adotado o cimento CPV- ARI Este cimento foi utilizado, pois não possui adições minerais pozolânicas que pudessem mascarar a provável pozolanicidade da cinza. Além disso, o teor de inerte deste cimento, máximo de $5 \%$ de materiais carbonáticos NBR 5733(ABNT, 1991), é o menor, dentre os cimentos disponíveis na região de Cruz das Almas.

A massa específica do cimento CPV- ARI utilizado é de $3,08 \mathrm{~g} / \mathrm{ml}$, a composição química e os índices físicos fornecidos pelo fabricante deste cimento são mostrados na Tabela 1.

\begin{tabular}{|c|c|c|c|c|}
\hline \multicolumn{2}{|c|}{$\begin{array}{c}\text { Composição Química } \\
(\%)\end{array}$} & \multicolumn{2}{|c|}{ Finura \% } & \multirow{2}{*}{$\begin{array}{l}\text { Blaine } \\
\mathrm{cm}^{2} / \mathrm{g}\end{array}$} \\
\hline $\mathrm{Fe}_{2} \mathrm{O}_{3}$ & 3,59 & $\# 200$ & $\# 325$ & \\
\hline $\mathrm{CaO}$ & 62,1 & 0,15 & 2,9 & 4.330 \\
\hline K2O & 0,54 & & & \\
\hline $\mathrm{SiO}_{2}$ & 20,54 & & & \\
\hline $\mathrm{SO}_{3}$ & 3,46 & & & \\
\hline $\mathrm{Al}_{2} \mathrm{O}_{3}$ & 3,8 & & & \\
\hline MgO & 2,56 & & & \\
\hline C3S & 56,11 & & & \\
\hline $\mathrm{CaOL}$ & 1,56 & & & \\
\hline P.F. & 4,81 & & & \\
\hline
\end{tabular}

FONTE: MIZU (2016).

A Tabela 2 apresenta a resistência à compressão do cimento Portland CPV-ARI em diferentes idades. Ensaio realizado em conformidade com a NBR 7215 (ABNT, 1996) e resultados fornecidos pelo fabricante.

Já para o cimento $C P \|-F$, os resultados fornecidos pelo fabricante da caracterização físicoquímica, são Massa Específica $3,08 \mathrm{~g} / \mathrm{cm}^{3}$, Área Específica (Blaine) $3.853 \mathrm{~cm}^{2} / \mathrm{g}$. 
TABELA 2: Resistência à compressão do cimento CP V-ARI em diferentes idades.

\begin{tabular}{lcc}
\hline Tempo & $\begin{array}{l}\text { Resistência à } \\
\text { compressão } \\
\text { (MPa) }\end{array}$ & $\begin{array}{l}\text { Limites de resistência à } \\
\text { compressão (MPa) NBR }\end{array}$ \\
\hline \hline $\mathbf{1}$ dia & 18,9 & 14 \\
\hline $\mathbf{3}$ dias & 22,3 & 24 \\
\hline $\mathbf{7}$ dias & 29,2 & 34 \\
\hline $\mathbf{2 8}$ dias & 35,7 & -- \\
\hline & & FONTE: MIZU (2015).
\end{tabular}

\subsubsection{Aditivo superplastificante}

Quando necessário, foi utilizado um superplastificante composto por policarboxilato que possuí massa especifica de $1,09 \mathrm{~g} / \mathrm{cm} 3$ para melhorar a fluidez da argamassa sem alterar a relação a/c.

\subsubsection{Agregado miúdo}

Nessa pesquisa foi empregada a areia mais utilizada pela construção civil na cidade de Cruz das Almas-BA. A determinação da distribuição granulométrica dessa areia foi feita através do peneiramento, de acordo com a NM 248 (ABNT, 2005), com emprego de um conjunto de peneiras da série normal e acopladas a agitador mecânico, onde permaneceram por $20 \mathrm{~min}$. As características físicas da areia utilizada são mostradas na Figura 3 e na Tabela 3. Da tabela é possível observar que o modulo de finura da areia utilizada atende a faixa recomendada pela norma.

\subsection{5 Água}

Para a produção das argamassas foi utilizada água potável da rede de abastecimento da Universidade Federal do Recôncavo da Bahia (UFRB). Não foram realizados ensaios para a determinação dos componentes da agua, tais como sulfatos e cloretos.

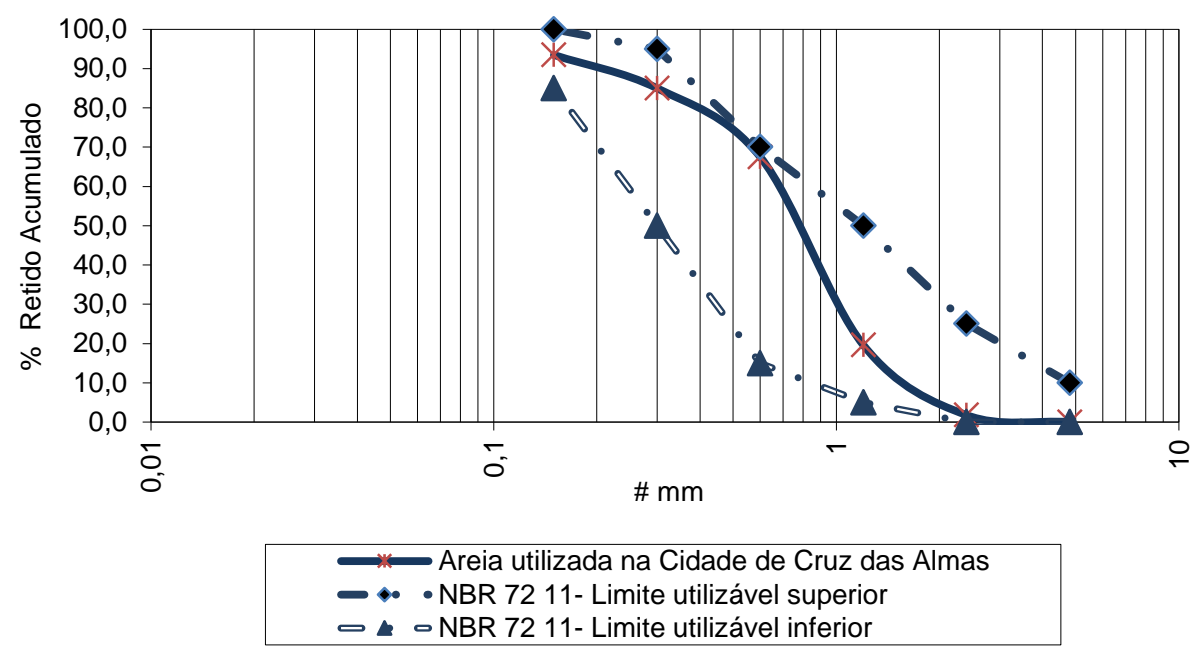

FIGURA 3: Curva granulométrica da areia utilizada. FONTE: Autor (2016).

\section{TABELA 3: Características físicas da areia utilizada.}

Dimensão máxima característica (mm) - NBR NM 248 (ABNT,2003)

Módulo de finura - NBR NM 248 (ABNT, 2003)

Massa específica (g/cm³) - NBR 9776 (ABNT, 1987).
2,4

2,51

2,60 


\subsection{MÉTODOS}

Para realização dessa pesquisa foram produzidas argamassas com diferentes concentrações de CCCV e as mesmas foram avaliadas no estado fresco e endurecido. 0 método de mistura das argamassas beseou-se na NBR 7215 (ANBT, 1996). Para a mistura foi utilizado argamassadeira de bancada com capacidade máxima de 5 litros. Para os ensaios de estado endurecido, os corpos de prova foram mantidos nos moldes por 24 horas e, em seguida, foram desmoldados e colocados em cura submersa em água saturada com cal até a idade de ensaio, 28 dias.

A Tabela 4 apresenta as massas dos componentes das argamassas, traço 1:3, com diferentes teores de substituição do CP. Ou seja, sem o resíduo $C C C V$, denominado por referência (ref), com teores de substituição, em massa, do cimento Portland nos teores de $5 \% \quad(5 \% \mathrm{CCCV}), 10 \%$ (10\%CCCV) e $15 \%$ (15\% CCCV). Este traço foi definido tomando por referência o traço sugerido pela NBR 7215 (ANBT, 1996). Estas argamassas foram analisadas no estado fresco através dos ensaios de consistência e densidade de massa, e no estado endurecido através do ensaio de índice de pozolanicidade, resistencia à tração na flexão e à compressão, absorção por imerção e por capilaridade.

\subsection{1 Índice de Atividade Pozolônica (IAP)}

Para verificar se a cinza da casca do coco tem potencial pozolânico e se atende a alguns dos requisitos estabelecidos na NBR 12653 (ABNT, 2014), foi relizado o ensaio de Índice de Atividade Pozolânica com cimento Portland prescrito na NBR 5752 (ABNT, 2014). Essa norma traz que é necessário o uso de areia normal para realização desse ensaio. Como não foi possível o uso de areia normal, foi feito um peneiramento das duas areias e utilizou-se apenas as frações granulométricas previstas na norma NBR 7214 (ABNT, 2015) (Figura 4). Para este ensaio foi utilizado o traço de $1: 3 \mathrm{com} a / c=0,48$, exatamente como recomenda a NBR 5752 (ABNT, 2014).

TABELA 4: Dosagem em massa dos quatro tipos de argamassa produzidos.

\begin{tabular}{|c|c|c|c|c|}
\hline \multirow[b]{2}{*}{ Material } & $0 \% \mathrm{CCCV}$ & $5 \% \mathrm{CCCV}$ & $10 \% \mathrm{CCCV}$ & $15 \% \mathrm{CCCV}$ \\
\hline & \multicolumn{4}{|c|}{ Dosagem em massa (g) } \\
\hline Cimento & 660 & 627 & 594 & 561 \\
\hline Cinza & 0 & 33 & 66 & 99 \\
\hline Areia & 1980 & 1980 & 1980 & 1980 \\
\hline Água & 330 & 330 & 330 & 330 \\
\hline Aditivo & 0 & 0,99 & 1,32 & 2,31 \\
\hline \multicolumn{5}{|c|}{ Traço 1:3 com a/c=0,5 } \\
\hline
\end{tabular}

FONTE: Autor (2016).

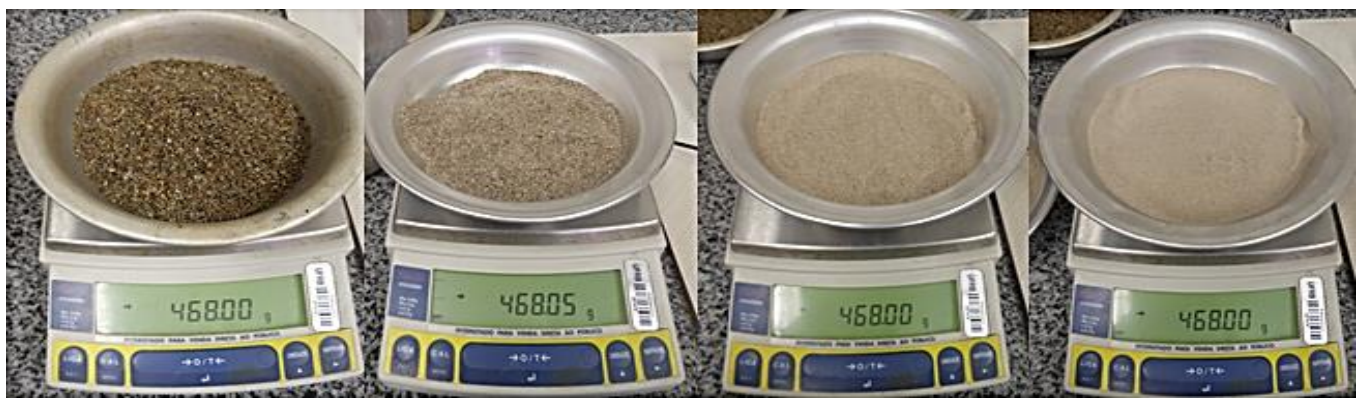

FIGURA 4: Frações granulométricas.

FONTE: Autor (2016) 
Esta norma recomenda a moldagem de quatro a seis corpos de prova cilindricos de $(50 \times 100)$ $\mathrm{mm}$ para cada um dos dois tipos de argamassa, cujo procedimento de moldagem deveseguir a NBR 7215 (ABNT, 1996). Foram moldados seis corpos de prova da argamassa tipo $A$, referência, com $0 \%$ de CCCV e mais seis corpos de prova da argamassa do tipo $B$, com $25 \%$ de CCCV. Estes corpos de prova foram mantidos em cura submersa por 27 dias, após um dia na forma, quando foram ensaiados a compressão axial.

Do ensaio de resistência a compressão é possível calcular o índice de atividade pozolânica da cinza. Este índice é dado pela relação entre a resistência média à compressão axial ( $\mathrm{MPa}$ ) dos corpos de prova da Argamassa tipo B e da Argamassa tipo $\mathrm{A}$, em porcentagem.

\subsubsection{Propriedades da Argamassa no Estado Fresco}

É de suma importância a determinação das propriedades da argamassa no estado fresco uma vez que estas propriedades estão diretamente ligadas a trabalhabilidade da argamassa e ao desempenho mecânico das mesmas. Sendo assim, foram feitos dois ensaios no estado fresco a fim de determinar a densidade de massa e a consistência das argamassas de acordo com a NBR 13278(ABNT, 2005) e a NBR 7215(ABNT, 1996), respectivamente. Os dois ensaios foram feitos para a argamassa de referência ( $0 \%$ CCCV) e para as argamssas com diferentes teores de substituição do CP V-ARI por $\operatorname{CCCV}(5 \%, 10 \%$ e $15 \%)$.

\subsubsection{Propriedades Mecânicas}

A análise de resistência dos materiais utilizados em projetos de engenharia é de fundamental importância. Diante disso, analisaremos as propriedades mecânicas da argamassa com diferentes concentrações da cinza para compreender a influência dessa adição nas resistências mecânicas das argamassas. Para isso, foram moldados seis corpos de prova prismáticos, para cada teor de cinza, e os mesmos foram ensaiados aos 28 dias. Os corpos de prova foram analisados pelos procedimentos do ensaio de resistência à tração na flexão e à compressão, transcrito pela NBR 13279(ABNT, 2005). Todas as rupturas foram feitas na prensa universal do modelo SDW series microprocessor control universal testing machine.

\subsubsection{Absorção Total e Capilar}

Absorção é um importante parâmetro para mensurar a durabilidade das argamassas. Sendo assim, foram realizados ensaios de absorção de água por capilaridade NBR 9779(ABNT,2005) e de absorção por imersão NBR 9778(ABNT, 2009). Este ensaio foi feito variando o teor de cinza das argamassas. Para cada teor de cinza (0\%, 5\%, 10\%, $15 \%)$ foram moldados seis corpos de prova cilindricos que após 1 dia de cura no molde e 27 dias submerso em água saturada em cal, foram submetidos aos ensaios de absorção. Três corpos de prova de cada teor foram submetidos ao ensaio de absorção por caplaridade e os outros três foram submetidos ao ensaio de absorção por imersão.

\section{RESULTADO E DISCUSSÕES}

Os resultados da inserção das cinzas da casca de coco verde apontam a viabilidade de inserção desse resíduo como adição mineral inerte. Portanto, sem propriedades pozolânicas. A seguir serão apresentados os resultados das propriedades das argamassas nos estados fresco e endurecido.

\subsection{CINZA DA CASCA DO COCO VERDE}

A CCCV produzida possui uma massa específica de $2,22 \mathrm{~g} / \mathrm{cm}^{3}$. Por meio da utilização do pHmetro de mesa foi possível observar que ao inserir a cinza CCCV em meio aquoso, houve uma alteração no $\mathrm{pH}$ da água tornando-a básica. A inserção de cerca $2 \mathrm{~g}$ de CCCV altera o pH da água destilada, de 7,0, para 12 .

\subsection{ARGAMASSA NO ESTADO FRESCO}

No estado fresco, a trabalhabilidade é a propriedade das argamassas que está associada à facilidade com que elas podem ser misturadas, transportadas e aplicadas, em uma condição homogênea (CARASEK, 2007). Ao fazer a 
substituição parcial do cimento Portland pela CCCV foi possível notar, de forma qualitativa, que a argamassa se tornou menos trabalhável, sendo necessária a adição de mais água para a mistura ficar com a mesma fluidez da argamassa de referência ${ }^{8}$. O que indica que a cinza produzida, provavelmente, possuí uma superfície específica maior que a do cimento, aumentando assim a demanda por água da mistura. Em função dessa característica, foi necessário empregar aditivo superplastificante para manter a relação a/c e garantir a trabalhabilidade.

Para suprir essa demanda por água sem alterar a relação $a / c=0,5$, adicionou-se um aditivo superplastificante (SP). 0 teor do aditivo 9 adicionado foi definido de forma empírica e variou em função da quantidade de cinza incorporada a mistura como mostra a Tabela 5 .

\subsubsection{Densidade de Massa}

A densidade de uma argamassa no estado fresco é uma propriedade importante que interfere na trabalhabilidade e na produtividade do operário, uma vez que quanto maior a densidade da argamassa, mais esforço ele terá que fazer para manuseá-la (CARASEK, 2007). Esta propriedade está associada às características dos componentes da argamassa.

TABELA 5: Porcentagem em massa do superplastificante adicionado em função do teor de cinza adicionada

\begin{tabular}{cc} 
Teor de cimento substituído por cinza & Teor aditivo SP adicionado \\
\hline $5 \% C C C V$ & $0,15 \%$ \\
\hline $10 \% C C C V$ & $0,30 \%$ \\
\hline $15 \% C C C V$ & $0,45 \%$ \\
\hline
\end{tabular}

FONTE: Autor (2016)

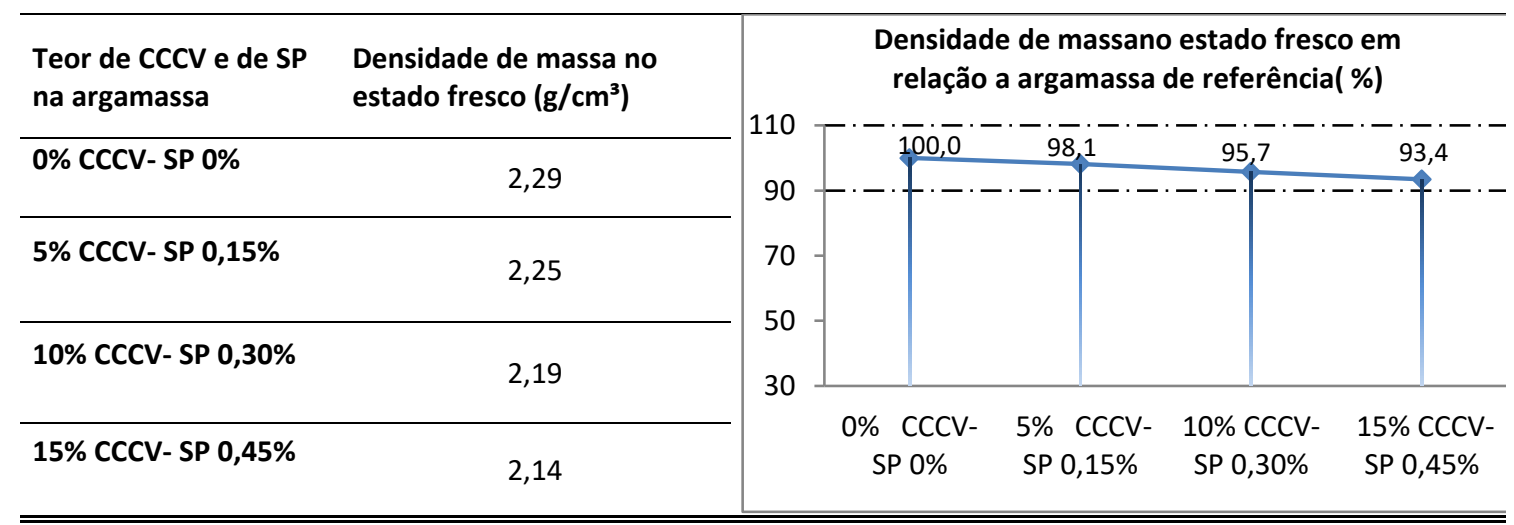

FIGURA 5: Valores de densidade de massa no estado fresco para os diferentes teores de cinza. FONTE: Autor (2016).

${ }^{8}$ Argamassa de referência: Sem CCCV, com 100\% de cimento CP V-ARI

\footnotetext{
${ }^{9}$ Porcentagem da massa de cimento utilizada no traço de
} referência com $100 \%$ de CP V-ARI. 
Uma vez que a densidade de massa da argamassa depende da massa específica de cada um dos seus componentes e de suas concentrações na mistura, é esperado que ocorra essa redução na densidade ao substituir CP V pela CCCV, pois a massa específica da cinza produzida $\left(2,22 \mathrm{~g} / \mathrm{cm}^{3}\right)$ é menor que a do $C P \vee\left(3,08 \mathrm{~g} / \mathrm{cm}^{3}\right)$. Mas a partir deste ensaio pode-se perceber que ao aumentar 0 teor de substituição do cimento Portland CPV-ARI pela CCCV, houve uma leve redução na densidade de massa da mistura, como mostra a Figura 5. A argamassa com um teor de $15 \%$ de CCCV apresentou uma redução na densidade de massa próxima a $7 \%$ em relação a argamassa de referência.

\subsection{2 Índice de consistência}

O índice de consistência (IC) representa uma das propriedades mais importantes da argamassa no estado fresco, que é a consistência. Essa propriedade está ligada à fluidez da mistura e traduz a tendência de deformação da argamassa quando submetida à ação de cargas. A consistência das argamassas produzidas foi aferida com base no espalhamento que elas apresentaram após sofrerem uma série de golpes, como recomenda a NBR 13276 (ABNT, 2005). Após os golpes, quanto maior for o espalhamento da argamassa sobre a mesa, menor é a sua resistência ao escoamento e, portanto, maior é a sua fluidez.
Da Figura 6, pode-se perceber que para um teor de substituição CP V-ARI por CCCV de até $10 \%$ o espalhamento da argamassa se manteve praticamente constante. $O$ que implica que até esse teor a substituição parcial do CP pela CCCV pouco influencia na consistência da argamassa. Mas, à medida que aumenta o teor de substituição do CP VARI por CCCV para $15 \%$, houve uma redução no espalhamento da argamassa, o que implica em menores índices de consistência. Além disso, percebe-se que mesmo fazendo uso do aditivo superplastificante, a quantidade adicionada não foi suficiente para garantir que a argamassa $15 \%$ CCCV apresentasse a mesma consistência da argamassa de referência.

Esse comportamento pode estar associado ao provável elevado caráter iônico da CCCV, que confere aos componentes da argamassa uma elevada higroscopia (Figura 7). A ionicidade do composto aumenta as interações eletrostáticas entre a CCCV e a água (BROWN e HOLME, 2009) e essa propriedade, aumenta a retenção de água pelos íons, reduzindo assim a quantidade de água livre na mistura. Essa possível redução da água livre da mistura, justifica o decréscimo do espalhamento, uma vez que essa água é responsável por reduzir o atrito entre os grãos da argamassa tornando-a mais fluida.

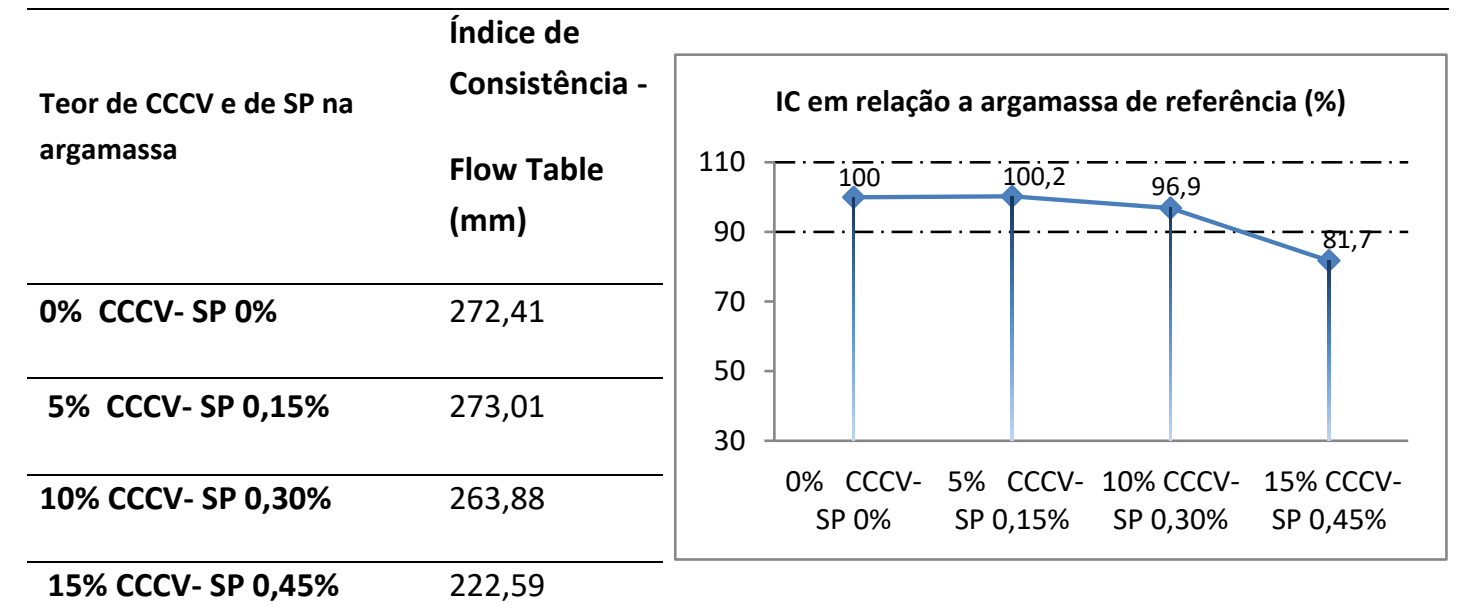

FIGURA 6: Avaliação do índice de Consistência para os diferentes teores de substituição do CP V-ARI por CCCV. FONTE: Autor (2016). 


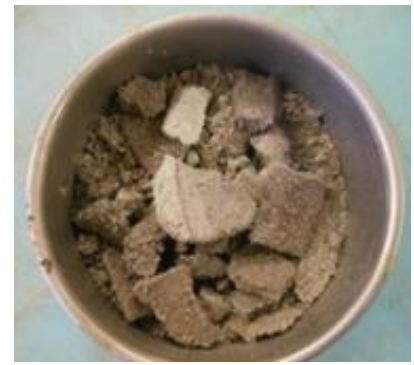

FIGURA 7: Cinza aglomerou após entrar em contato com a umidade do ambiente. FONTE: Autor (2016).

\subsection{ARGAMASSA ESTADO ENDURECIDO}

\subsubsection{Pozolanicidade}

O potencial pozolânico de uma cinza pode ser inferido através da análise do ensaio do índice de desempenho com cimento Portland aos 28 dias. A Tabela 6 traz o resultado dessa análise feita para a cinza estudada. Este ensaio mostrou que a CCCV possui $26,3 \%$ de índice de pozolanicidade, resultado próximo ao obtido por Milani et al. (2009) ${ }^{10}$, confirmando assim que esta cinza não possui potencial pozolânico, pois não atende ao IP mínimo de 75\% previsto na NBR 12653 (ABNT, 2014).

$\mathrm{O}$ que indica que a CCCV não reagiu com o $\mathrm{Ca}(\mathrm{OH}) 2$ resultante da hidratação do cimento formando $\mathrm{C}-\mathrm{S}-\mathrm{H}$, e consequentemente não possui caráter pozolânicos.

\subsubsection{Propriedades Mecânicas}

Os resultados obtidos mostraram uma redução na resistência mecânica da argamassa, à medida que aumentava o teor de substituição do CP por CCCV. Resultados similares foram obtidos por Milani et al. (2009).

\subsubsection{Resistência à tração na flexão}

O algomerante é o material constituinte da argamassa que é responsável por conferir resistência ao esforço de tração, uma vez que os agregados não possuem a coesão necessária para resistirem a este esforço. Sendo assim, a partir do momento que reduz a quantidade de aglomerante na mistura, menos produtos da hidratação do cimento Portland serão formados, e consequentemente, menor será a resistência mecânica da argamassa, a menos que este fator seja compensado pelo efeito microfiler das partículas inseridas.

Da Figura 8 é possível perceber que ao substituir parcialmente o CPV-ARI por cinza, verificou-se uma redução na resistência à tração da argamassa. Para os teores de $5 \%$ e $10 \%$ de substituição do $\mathrm{CP} \vee$ por $\mathrm{CCCV}$, a resistencia aproximadamente $85 \%$ e $81 \%$ da resistencia da argamassa de referencia, respectivamente. Já para a argamassa com $15 \%$ de cinza essa resistencia caiu aproximadamente para $50 \%$ da resistencia à da argamassa de referência. Este resultado já era esperado, uma vez que do ensaio de pozolanicidade concluíu-se que a CCCV não possui caraterísticas pozolânicas e, portanto, não incrementa C-S-H à mistura, o que provoca uma redução na resistência à tração na flexão.

TABELA 6: Resultados do ensaio de índice de atividade pozolânicas normatizado pela NBR 5752 (ABNT,2014).

\begin{tabular}{ccc} 
& Argamassa A (0\% CCCV) & Argamassa B (25\% CCCV) \\
\cline { 2 - 3 } Resistência Média à Compressão aos 28 dias (Mpa) & 33,0 & 8,7 \\
\hline DP & $5,9 \%$ & $20,3 \%$ \\
\hline CV & 0,2 & 2,3 \\
\hline IP & & $26,30 \%$ \\
\hline
\end{tabular}

FONTE: Autor (2016)

\footnotetext{
${ }^{10}$ Milani et al. (2009), diz que a CCCV(cinza da casca do coco verde) possui índice de atividade pozolanica de $25 \%$.
} 


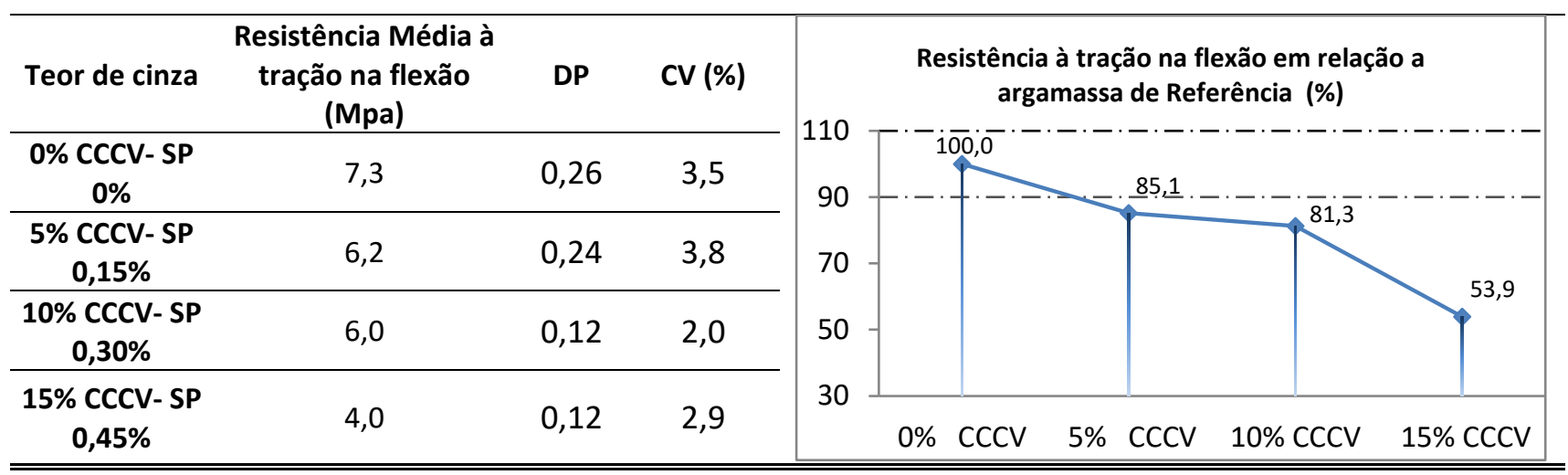

FIGURA 8: Resultados do ensaio de resistência à tração na flexão, feito com base na NBR 13279(ABNT,2005). FONTE: Autor (2016).

Apesar disso, essa redução não compromete uso da CCCV em argamassas, pois argamassas não costumam trabalhar sob o esforço de tração na flexão e por isso esta propriedade, no geral, não é importante para este material.

\subsubsection{Resistência à compressão}

Todas as partículas constituintes da argamassa (agregados, grãos de cimento não hidratados, etringita, e outros produtos da hidratação) são responsáveis por resistir ao esforço de compressão (DAL MOLIN, 2005). Ao substituir parte do cimento por material inerte, ocorre uma redução na quantidade de produtos da hidratação do cimento que ajudariam a resistir aos esforços de compressão, reduzindo assim a resistência à compressão da argamassa. Entretanto, esta redução de resistência provocada pela diluição do cimento pode ser compensada caso o material promova o efeito de redistribuição granulométrica melhorando a compacidade da mistura (OLIVEIRA, 2000).
A Figura 9 mostra os resultados do ensaio de resistência à compressão. Para os teores de $5 \%$ e $10 \%$, pode-se notar uma redução pouco expressiva nesta resistência, em torno de $1 \mathrm{MPa}$, em relação a argamassa de referência. Já para o teor de substituição de 15\%, a resistência à compressão corresponde a apróximadamente $78 \%$ da resistência da argamassa de referência.

Sendo assim, este ensaio mostra a possibilidade de utilizar esta cinza como adição mineral inerte, em substituição ao cimento Portland para um teor de até $10 \%$. Isto porque, a substituição do CP por partículas inertes, como é o caso da CCCV, causa o efeito de diluição do cimento. Todavia, até um teor de $10 \%$ de substituição parcial do CP por CCCV, houve uma variação pouco expressiva da resitência, o que indica que o efeito de redistribuição granulométrica causado pela CCCV foi suficiente para compensar esse efeito de diluição do cimento manter a resistência à compressão.

\begin{tabular}{|c|c|c|c|c|c|}
\hline $\begin{array}{l}\text { Teor de } \\
\text { cinza }\end{array}$ & $\begin{array}{c}\text { Resistência Média à } \\
\text { Compressão (Mpa) }\end{array}$ & DP & CV (\%) & \multirow{2}{*}{\multicolumn{2}{|c|}{$\begin{array}{l}\text { Resistência à compressão em relação a } \\
\text { resistência da argamassa padrão (\%) }\end{array}$}} \\
\hline 0\% CCCV- & 32,7 & 0,33 & \multirow{2}{*}{1,0} & & \\
\hline SP 0\% & \multirow[b]{2}{*}{31,3} & \multirow[b]{2}{*}{0,30} & & \multirow{2}{*}{$\begin{array}{r}110 \\
90\end{array}$} & $95,7-\cdot-\cdot-1$ \\
\hline SP 0,15\% & & & 0,9 & & $\cdot-\cdot-\cdot--\cdot-\cdot-\cdot-$ \\
\hline $\begin{array}{l}10 \% \text { CCCV- } \\
\text { SP } 0,30 \%\end{array}$ & 30,4 & 0,42 & 1,4 & $\begin{array}{l}70 \\
50\end{array}$ & \\
\hline \multirow{2}{*}{$\begin{array}{l}15 \% \text { CCCV- } \\
\text { SP } 0,45 \%\end{array}$} & \multirow{2}{*}{25,4} & \multirow{2}{*}{0,27} & \multirow{2}{*}{1,1} & 30 & \\
\hline & & & & \multicolumn{2}{|r|}{$0 \% \operatorname{CCCV} \quad 5 \% \operatorname{CCCV} 10 \% \operatorname{CCCV} 15 \%$ CCCV } \\
\hline
\end{tabular}

FIGURA 9: Resultados do ensaio de resistência à compressão, feito com base na NBR 13279 (ABNT, 2005). FONTE: Autor (2016). 


\subsubsection{Durabilidade}

A durabilidade de uma argamassa está associada, entre tantos fatores, à porosidade da mesma, uma vez que a ação dos agentes deletérios, presentes no ambiente, é facilitada pela porosidade aberta da argamassa. Para avaliar esta propriedade foram feitos os ensaios de absorção por imersão e por capilaridade. Constatou-se que as argamassas com CCCV, no geral, apresentaram uma absorção maior que a argamassa de referência, tanto por imersão quanto por capilaridade.

\subsubsection{Absorção por imersão}

A Figura 10 mostra que a inserção da cinza na mistura provocou um aumento na porcentagem de água absorvida por imersão. Pode-se perceber que para um teor de substituição de $5 \%$ de CP por CCCV houve uma variação pouco expressiva na porcentagem de absorção por imersão, de aproximadamente $10 \%$, quando comparado à argamassa de referência. Do gráfico de crescimento mostrado na Figura 10, pode-se perceber uma tendência linear de crescimento da porcentagem de absorção por imersão em relação a da argamassa de referência.

Tanto maior teor de substituição do CP V ARI por CCCV, maior a absorção por imersão. Esses resultados convergem com a avaliação da resistência à compressão. Afinal, tanto maior a porosidade de uma argamassa, menor a resistência a compressão. Esse fenômeno pode ser explicado por meio do efeito de diluição do CP. Tanto maior a diluição, menor o teor de C-S-H produzido e, consequentemente, menor o preenchimento dos poros pelos produtos da hidratação.

Deste ensaio, pode-se concluir que até um teor de $5 \%$ de CCCV não há uma variação expressiva na absorção por imersão.

\subsubsection{Absorção por capilaridade}

O ensaio de absorção por capilaridade confirma que a absorção de água na argamassa aumenta à medida que aumenta o teor de CP substituído por CCCV. Da Figura 11, pode-se observar que para o teor de substituição de $5 \%$ de CP por CCCV, houve um acréscimo INFERIOR A 10\% da absorção capilar quando comparada a absorção da argamassa de referência. Já para o dobro de cinza a absorção aumenta cerca de quatro vezes, chegando a um valor próximo de $21 \%$. Por fim, para um teor de15\% de CCCV essa absorção chegou a ser $61 \%$ maior do que a absorção da argamassa de referência.

Este aumento na absorção indica que a argamassa se tornou mais porosa com a adição da cinza e este o que contribuí para a redução da resistência mecânica das argamassas com CCCV. A inserção da cinza além de ter interferido na quantidade de $\mathrm{C}-\mathrm{S}-\mathrm{H}$ formado, pode ter interferido na distribuição das partículas solidas aumento assim o índice de vazios e a quantidade de poros intercomunicáveis na argamassa. Apesar disto, para um teor de até $5 \%$ de substituição do $\mathrm{CP}$ por CCCV, não há uma variação expressiva na absorção quando comparada a argamassa de referência.

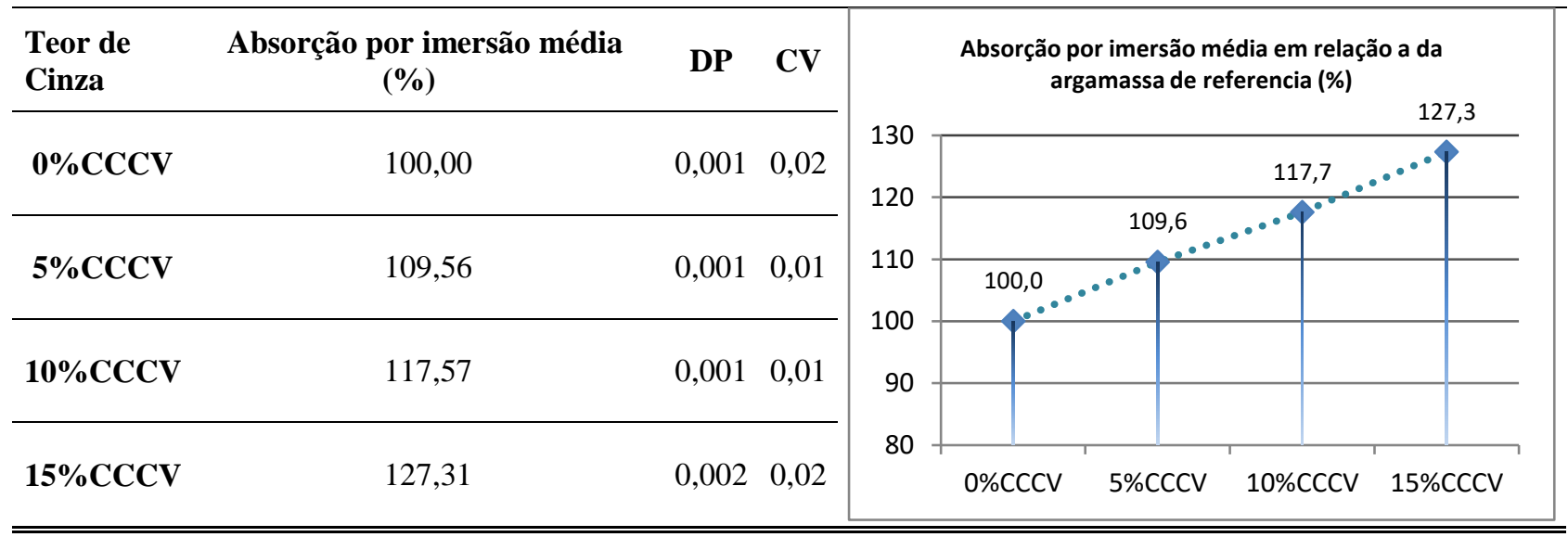

FIGURA 10 Resultado do ensaio de absorção por imersão, NBR 9778 (ABNT,2005).

FONTE: Autor (2016) 


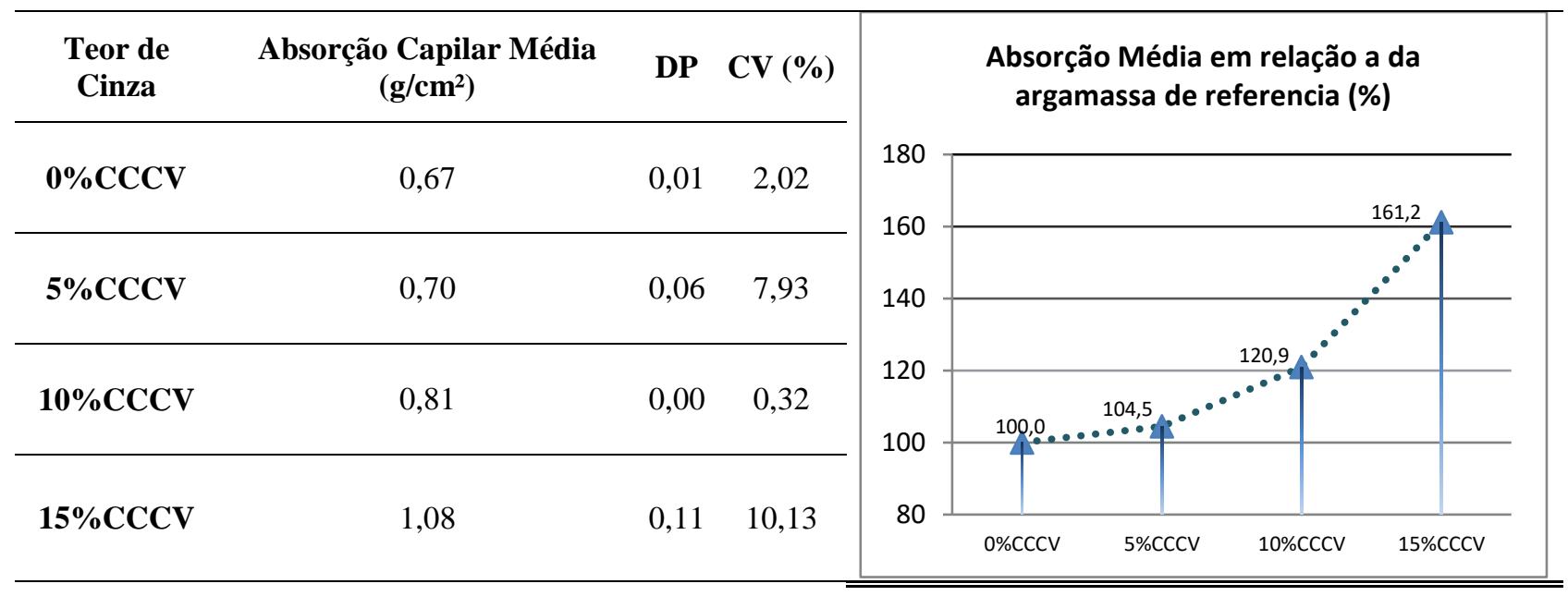

FIGURA 11: Resultados do ensaio de absorção por capilaridade, NBR 9779 (ABNT,2005). FONTE: Autor (2016).

\section{CONCLUSÕES}

Algumas empresas, na Bahia, já empregam a casca de coco para produzir energia térmica, nas caldeiras, para suprir parte da demanda energética do processo produtivo. Nesse contexto, a geração de cinzas torna-se um problema ao qual a inserção desse resíduo em matriz cimentícias é uma alternativa para a adequada gestão do resíduo. A variação pouco expressiva na resistência a compressão para um teor de substituição de até $10 \%$ indica que a CCCV pode ser utilizada como adição inerte. Além disso, pode-se destacar que:

- No estado fresco a presença da cinza da casca de coco verde interfere diretamente na consistência tornando a mistura menos fluída;

- Ao variar o teor de substituição, houve uma redução pouco expressiva na densidade de massa da argamassa quando comparada a argamassa de referência;

- Pelo método estudado, a cinza da casca do coco verde não atendeu as exigências normativas de índice de pozolanicidade e por isso não pode ser considerada uma adição mineral pozolânica;

- $\quad$ Através dos ensaios de absorção por imersão e por capilaridade, pode-se perceber que a inserção da cinza a um teor de até $5 \%$ não interfere de forma expressiva na absorção de água da argamassa. Indicando que a configuração de vazios conectados para este teor de CCCV se manteve semelhante à da argamassa de referência.

À medida que aumenta o consumo de coco, aumenta a produção de resíduo de casca. No entanto, após seca, a casca de coco verde apresenta potencial de queima na caldeira de diversas empresas que produzem derivados de coco. 0 resíduo mineral, após a queima da casca, não tem um destino, frequentemente, apropriado. A inserção das CCCV em matrizes de cimento Portland é uma alternativa para a destinação adequada para o resíduo. Isso porque a substituição do cimento Portland por CCCV minimiza o impacto ambiente da produção do clínquer e não altera significativamente as propriedades das matrizes, até teores de $10 \%$.

\section{REFERÊNCIAS BIBLIOGRÁFICAS}

ABDUL-WAHAB, Sabah A.. Impact of fugitive dust emissions from cement plants on nearby communities. Science Direct, Muscat, p.338-348, 2006.

ASSOCIAÇÃO BRASILEIRA DE NORMAS TECNICAS (ABNT). NBR 7215: Cimento Portland Determinação da resistência à compressão. Rio de Janeiro, 1996.

NBR 11578: Cimento Portland composto Especificação. Rio de Janeiro, 1991.

NBR 12653: Materiais pozolânicos Requisitos. Rio de Janeiro, 2014.

NBR 13281: Argamassa para assentamento e revestimento de paredes e tetos - Requisitos. Rio de Janeiro, 2005.

NBR 13280: Argamassa para assentamento e revestimento de paredes e tetos - Determinação da densidade de massa aparente no estado endurecido. Rio de Janeiro, 2005. 
NBR 13277: Argamassa para assentamento e revestimento de paredes e tetos - Determinação da retenção de água. Rio de Janeiro, 2005.

NBR 13528: Revestimento de paredes e tetos de argamassas inorgânicas - Determinação da resistência de aderência à tração. Rio de Janeiro, 2010.

. NBR 7214: Areia normal para ensaio de cimento - Especificação. Rio de Janeiro, 2015.

. NBR 9779: Argamassa e concreto endurecidos Determinação da absorção de água por capilaridade. Rio de Janeiro, 1995.

NBR 9778: Argamassa e Concreto Endurecidos Determinação da Absorção de Água por Imersão Índice de Vazios e Massa Específica. Rio de Janeiro, 2005.

NBR 13278: Argamassa para assentamento e revestimento de paredes e tetos - Determinação da densidade de massa e do teor de ar incorporado. Rio de Janeiro, 2005

NBR 13279: Argamassa para assentamento e revestimento de paredes e tetos - Determinação da resistência à tração na flexão e à compressão. Rio de Janeiro, 2005

NBR 15259: Argamassa para assentamento e revestimento de paredes e tetos - Determinação da absorção de água por capilaridade e do coeficiente de capilaridade. Rio de Janeiro, 2005

NBR 5752: Materiais PozolanicosDeterminação do índice de desempenho com cimento Portland aos 28 dias. Rio de Janeiro,2014

NBR 5733: Cimento Portland de Alta Resistencia Inicial. Rio de Janeiro,1991.

NBR 11172: Aglomerantes de origem mineralTerminologia. Rio de Janeiro, 1990.

NM 248: Agregados- Determinação da composição granulométrica. Rio de Janeiro, 1991.

. NM 23: Cimento portland e outros materiais em pó - Determinação da massa específica. Rio de Janeiro, 2001.

AGENCIA BRASIL. Ciência, Tecnologia e Meio Ambiente. Aproveitamento agroindustrial da casca de coco verde ainda é reduzido. 2004. Disponível em:< http://www.radiobras.gov.br> acesso 15 Nov 2015.

BENHELAL, Emad et al. Global strategies and potentials to curb $\mathrm{CO}_{2}$ emissions in cement industry. Journal of Cleaner Production, Lismore, n. 51, p.142-161, 2013.

BONAVETTI, V. L.; RAHHAL, V. F.. Interacción de Adiciones Minerales en Pastas de Cemento. Revista de La Construcción, Olavarría, v. 5, n. 2, p.33-41, 2006.
BROWN, Lawrence S.; HOLME, Thomas A.. Química Geral: Aplicada a Engenharia. São Paulo: Cengage Learning, 2009. $650 \mathrm{p}$.

CASTRO, A. L. de; PANDOLFELLI, V. C.. Revisão: Conceitos de dispersão e empacotamento de partículas para a produção de concretos especiais aplicados na construção civil. Cerâmica, São Carlos, n. 55, p.18-32, 2009. Disponível em: <http://www.scielo.br/pdf/ce/v55n333/03.pdf>. Acesso em: 18 ago. 2012.

CORDEIRO, Guilherme Chagas. Utilização de Cinzas Ultrafinas do Bagaço de Cana-de-Açúcar e da Casca de Arroz como Aditivos Minerais em Concreto. 2006. 445 f. Tese (Doutorado) - Curso de Engenharia Civil, Coppe, Universidade Federal do Rio de Janeiro, Rio de Janeiro,2006.Disponível em: <http://www.coc.ufrj.br/index.php/component/docman /cat_view/28-doutorado/62-2006?ltemid=>. Acesso em: 20 nov. 2015.

CORDEIRO, Guilherme Chagas; TOLEDO FILHO, Romildo Dias; FAIRBAIRN, Eduardo de Moraes Rego. Use of ultrafine rice husk ash with high-carbon content as pozzolan in high performance concrete. Materials And Structures, [s.I.], v. 42, n. 7, p.983-992, 12 out. 2008. Springer Science + Business Media. DOI: 10.1617/s11527008-9437-z.

CORRADINI, E.; ROSA, M. de F.; MACEDO, B. P. de; PALADIN, P. D.; MATTOSO, L. H. C Composição química, propriedades mecânicas e térmicas da fibra de frutos de cultivares de coco verde. Rev. Bras. Frutic., Jaboticabal SP, v. 31, n. 3, p.837-846, Setembro 2009 Disponívelem:<http://ainfo.cnptia.embrapa.br/digital/bi tstream/CNPAT2010/11725/1/PA09031.pdf> Acesso em: 08 dez. 2015.

CARASEK, H. Argamassas. In: Livro Materiais de Construção Civil. 1. ed. São Paulo, IBRACON, 2007.

DAL MOLIN, D. C. C. Adições Minerais para Concreto Estrutural. In: ISAIA, Geraldo C. (Ed). Concreto: Ensino, Pesquisa e Realizações. v.1. São Paulo, SP: IBRACON, 2005. Cap. 12, p. $345-379$.

DAL MOLIN, Denise Carpena. Concreto autoadensável. São Paulo: PINI, 2005.

FAO- Food and Agriculture Organization of the United Nations- 2014,Disponível em <http://www.fao.org/statistics/en/> Acesso em: 22 nov. 2015.

JESUS JR, L. A. et al.. Análise da produção da cultura do coco no Brasil, Nordeste e Sergipe. 6th International Symposium On Technological Innovation, Aracaju, v. 3, n. 1, p.317-324, 25 set. 2015. Anual. Universidade Federal de Sergipe. DOI:10.7198/s23183403201500030038.Disponívelem:<http://www.portalm 
ites.com.br/conferences/index.php/ENEE/Isti2015/pape r/viewFile/407/244>. Acesso em: 26 out. 2015.

LAWRENCE, Philippe; CYR, Martin; RINGOT, Erick. Mineral admixtures in mortars Effect of inert materials on shortterm hydration. Cement And Concrete Research, France, n. 33, p.1939-1947, 2003.

MARTINS, Carlos Roberto; JESUS JUNIOR, Luciano Alves de. Produção e comercialização de coco no Brasil frente ao comércio internacional : panorama 2014. Aracaju: Embrapa Tabuleiros Costeiros, 2014. 51 p. Documento 184. Disponível em: <http://ainfo.cnptia.embrapa.br/digital/bitstream/item/ 122994/1/Producaoecomercializacao-Doc-184.pdf>. Acesso em: 07 dez. 2015.

MEHTA, P. K.; MONTEIRO, P. J. M. Concreto Microestrutura, Propriedades e Materias - 2a Ed. Editora Ibracon, 2008.

MEHTA, P. K, "Properties of blended cements made from rice husk ash", $\mathrm{ACl}$ Journal, v. 74, n.40,pp.440442,1977.Disponível

em:<https://www.concrete.org/publications/internation alconcreteabstractsportal.aspx?m=details\& $\mathrm{i}=11022>$ Ace ssoem:30nov.de2015

MILANI, A.P.S.; BERTOCINI, S. R.; ARAÚJO, S. C.; SANTOS, V. P.; Ricci, T.G. Avaliação físico-mecânica de argamassas adicionadas de cinza de casca de coco verde. In: Congresso

BrasileirodeConcreto,51.Anais...Curitiba,2009.

NEVILLE, A. M., 1997, Propriedades do concreto, 2 ed. São Paulo: Editora Pini, 828p.

NOGUEIRA, L.A.H. et al.. Dendroenergia: fundamentos e aplicações. Brasília, DF:ANEEL - Agência Nacional de Energia Elétrica, 2000. 144 p.

OLIVEIRA, Ivone R. de et al.. Dispersão e empacotamento de partículas: princípios e aplicações em processamento cerâmico. São Paulo: Fazendo Arte Editorial, 2000.

SILVA, R. B.; FONTES, C. M. A.; LIMA, P. R. L.; GOMES, O. da F. M.; LIMA, L. G. L. M.; MOURA, R. C. de A.; TOLEDO FILHO, R. D. Cinzas de biomassa geradas na agroindústria do cacau: caracterização e uso em substituição ao cimento. Ambiente Construído, Porto Alegre,v. 15, n. 4, p. 321-334, out./dez. 2015. ISSN 1678-8621 Associação Nacional de Tecnologia do Ambiente Construído. http://dx.doi.org/10.1590/s1678-86212015000400053

SILVEIRA, Monica Silva. Aproveitamento das cascas de coco verde para produção de briquete em salvador ba. 2008. 163 f. Dissertação (Mestrado) - Curso de Mestrado em Gerenciamento e Tecnologias Ambientais no Processo Produtivo, Escola Politécnica, Universidade Federal da Bahia, Salvador, 2008. Disponível em: <http://www.teclim.ufba.br/sitbe/material_online/disse rtacoes/dis_monica_silveira.pdf>. Acesso em: 28 out. 2015.

VALLE, C.E. Qualidade ambiental: o desafio de ser competitivo protegendo o meio ambiente. São Paulo: Pioneira, 1995. não paginado.

WILLS, Williiam. Estudo 61: indústria de cimento. Disponível em: <http://web.cedeplar.ufmg.br/cedeplar/site/pesquisas/ pis/Estudo\%2061.pdf>. Acesso em: 06 jul. 2013. 